\title{
Risk factors for hypertensive disorders of pregnancy among mothers in Tigray region, Ethiopia: matched case-control study
}

Hailemariam Berhe Kahsay ${ }^{1 *}$, Fikre Enquselassie Gashe ${ }^{2}$ and Wubegzier Mekonnen Ayele ${ }^{2}$

\begin{abstract}
Background: Hypertensive disorders of pregnancy are a global public health concern both in developed and developing countries. However, evidences regarding the risk factors of hypertensive disorders of pregnancy are limited particularly in Ethiopia. The aim of the study was to assess risk factors associated with hypertensive disorders of pregnancy among mothers in public hospitals of Tigray.

Methods: The study was conducted in seven public hospitals of Tigray region, Ethiopia from June 2017 to November 2017. A facility based matched case-control study was employed to select 110 cases and 220 controls who were pregnant women. Cases and controls were matched by parity status. A case was a mother diagnosed to have hypertensive disorders of pregnancy by an obstetrician in the antenatal period while a control was a mother who did not have a diagnosis of hypertensive disorders of pregnancy. Data were collected by face to face interview technique using a pretested questionnaire and a checklist. Conditional logistic regression analysis was used to identify the independent predictor variables. Adjusted matched odds ratio with its corresponding 95\% confidence interval was used and significance was claimed at $P$-value less than 0.05 . Overall findings were presented in texts and tables.

Results: Rural residents were at greater odds of suffering from hypertensive disorders $(\mathrm{OR}=3.7,95 \% \mathrm{Cl} ; 1.9,7.1)$. Similarly, mothers who consume less amount of fruits in their diet had 5 times higher odds of developing hypertensive disorders than those who consume fruits regularly $(\mathrm{OR}=5.1,95 \% \mathrm{Cl} ; 2.4,11.15)$. Overweight $(\mathrm{BMl}>25 \mathrm{Kg} / \mathrm{m} 2)$ mothers were also at risk of developing hypertensive disorders of pregnancy as compared with the normal and underweight mothers ( $\mathrm{AOR}=5.595 \% \mathrm{Cl} ; 1.12,27.6)$. The risk of developing hypertensive disorders of pregnancy was 5.4 times higher among diabetic mothers.

Conclusion: Rural residence, less fruit consumption, multiple pregnancy, presence of gestational diabetes mellitus and pre-pregnancy overweight were identified as independent risk factors in this study. It is recommended that health care givers may use these factors as a screening tool for the prediction, early diagnoses as well as timely interventions of hypertensive disorders of pregnancy.
\end{abstract}

Keywords: Hypertensive disorders of pregnancy, Gestational hypertension, Preeclampsia, Tigray, Ethiopia

\footnotetext{
* Correspondence: aidhbk@gmail.com

'School of Nursing, Mekelle University, P.O.Box:1871, Mekelle, Ethiopia

Full list of author information is available at the end of the article
}

(c) The Author(s). 2018 Open Access This article is distributed under the terms of the Creative Commons Attribution 4.0 International License (http://creativecommons.org/licenses/by/4.0/), which permits unrestricted use, distribution, and reproduction in any medium, provided you give appropriate credit to the original author(s) and the source, provide a link to the Creative Commons license, and indicate if changes were made. The Creative Commons Public Domain Dedication waiver (http://creativecommons.org/publicdomain/zero/1.0/) applies to the data made available in this article, unless otherwise stated. 


\section{Background}

According to the American college of obstetricians and gynaecologists (ACOG), Hypertension in pregnancy is defined as: Systolic blood pressure greater than or equal to $140 \mathrm{mmHg}$ and/or diastolic blood pressure greater than or equal to $90 \mathrm{mmHg}$ in two occasions at least $6 \mathrm{~h}$ apart after fifth month of gestation for pregnancy induced hypertension or before pregnancy/before 20 weeks of gestation for chronic hypertension. Hypertensive disorders of pregnancy (HDP) refers to categories of conditions characterized by elevated blood pressure and classified as chronic hypertension (of any cause diagnosed before 20 weeks of gestation), gestational hypertension, chronic hypertension with superimposed preeclampsia and preeclampsia-eclampsia $[1,2]$.

Hypertensive disorder of pregnancy is one of the most common complications in pregnancy forming a triad together with hemorrhage and infection. It affects about $10 \%$ of pregnancies [3] and contributes for a significant maternal and perinatal mortality [4]. The World Health Organization (WHO) reported that $14.0 \%$ of global maternal deaths are attributed to hypertensive disorders of pregnancy [5]. In LatinAmerican and Caribbean countries 25.7\% of maternal deaths were due to hypertensive disorders of pregnancy; in Asian and African countries, it contributed to $9.1 \%$ of maternal deaths and in fact about $16 \%$ in sub-Saharan African countries [5-7].

Hypertensive disorder of pregnancy is a global public health concern both in developed and developing countries. However, the risk that a woman in a developing country will die of the complications of hypertensive disorders of pregnancy is approximately 300 times higher than that for a woman in a developed country. A woman who develops pre-eclampsia is three times more likely to progress to eclampsia and if eclampsia is developed it is up to 14 times more likely to die of eclampsia [8].

The Ethiopian National Emergency Obstetric and Newborn Care (EMONC) study showed that preeclampsia/eclampsia complicated $1.2 \%$ of all institutional deliveries. Besides, $11 \%$ of all maternal deaths and $16 \%$ of direct maternal deaths were due to this obstetric complication [9] in another study in Ambo, Ethiopia maternal mortality due to hypertensive disorders of pregnancy was reported to be $12.3 \%$ [10] . The Ethiopian government has implemented different strategies to improve maternal health through increasing demand for services and easier access to emergency obstetric services. Expansion of health facilities, increased availability of supplies and deployment of appropriately skilled health professionals were among the strategies [11].

Despite the extensive research conducted the exact etiology of hypertensive disorders of pregnancy remained obscure. Thus, it is called a "disease of theories." It is a multisystem disease with a heterogeneous nature and variable progression [12]. It has been proposed that immunological, nutritional and genetic factors as well as vascular and inflammatory changes are contributing for the development of hypertensive disorders of pregnancy [4].

Cognizant that the disease has no definite cause, several studies focusing on risk factors have been conducted in different parts of the globe and identified various risk factors for hypertensive disorders of pregnancy. These risk factors include socio-demographic variables such, personal and lifestyle factors, obstetric related factors, familial factors and medical related variables [13-16]. Specifically, nulliparity, extreme ages, obesity, a family history of hypertension, previous history of hypertensive disorders of pregnancy in multipara women, personal/ family history of chronic hypertension/diabetes mellitus, high energy diet, gestational diabetes, mental stress during pregnancy, long inter-pregnancy interval, lower socioeconomic status and inadequate antenatal supervision were found to be associated with higher risk of developing hypertensive disorders of pregnancy in most studies [17-22]. Studies identified rural residence as a risk factor [23] and taking fruit or vegetables during pregnancy were found to be protective of hypertensive disorders of pregnancy [19].

Generally, maternal mortality due to hypertensive disorders of pregnancy remained high in spite of all the efforts. Studies conducted in different parts of the globe reported a range of risk factors though findings were not conclusive showing variations among populations and ethno-geographic groups. Moreover, inconsistent findings prevail across literatures even for a particular risk factor. Besides, there is paucity of evidence regarding factors associated with hypertensive disorders of pregnancy in Ethiopia. Even the few published studies conducted in Ethiopia were based on a document review which might have introduced bias due to incompleteness and poor quality of the data at the health facility $[24,25]$. Thus, the current study attempted to assess risk factors for hypertensive disorders of pregnancy in Tigray region to generate evidences which are most relevant to support health policies and strategies.

\section{Methods}

\section{Study setting and period}

This study was conducted in selected public hospitals in Tigray region. Seven hospitals were included in the study namely Ayder, Mekelle, Adigrat, St. Marry, Suhul, Lemlem Carl and Kahsay Abera hospital. The six hospitals are located at the centre of the six respective zones of Tigray region mainly serving the people of the zones. Ayder referral hospital is found in Mekelle city serving as a referral hospital for about 8 million people from the 
entire Tigray region and partly from Afar and Amhara regions. In Tigray region, there are 28 health facilities providing basic emergency obstetrics and newborn care (BEmONC) and 15 facilities providing comprehensive emergency obstetrics and newborn care respectively [26]. The selected hospitals provide services for substantial number of patients with and without obstetrics complications. These hospitals are selected in this study due to the fact that they are staffed by obstetricians who can correctly diagnosed hypertensive disorders of pregnancy and relatively equipped by diagnostic facilities. Data were collected from June 2017 to November 2017.

\section{Study design}

A facility based matched case control study was employed. These women were pregnant mothers attending antenatal care clinics in the study hospitals. Cases and control were matched in parity, time and site of the study. The case and control mothers were included after 20 weeks of gestation as per the diagnosis and the criteria set.

\section{Study population}

The study population were all pregnant mothers attending the maternity centers of the study hospitals. Mothers with a history of confirmed chronic hypertension or diagnosed before 20 weeks gestation which is greater than or equal to $140 / 90 \mathrm{mmHg}$ and without superimposed preeclampsia were excluded from the study because chronic hypertension can be a risk factor for preeclampsia but not for gestational hypertension. Since we measured the different hypertensive disorders as a single outcome, chronic hypertension was excluded as it can be an outcome and a risk factor at the same time. Chronic hypertensive women superimposed with preeclampsia-eclampsia was included as an outcome because this category has common exposure as the rest of the categories.

A case was defined as a mother diagnosed to have hypertensive disorders of pregnancy by an obstetrician in the antenatal period (international classification of disease/ICD - 10 codes O13, O14 and O15 [27]). Hypertensive disorders of pregnancy included gestational hypertension, preecalampsia-eclampsia and preeclampsia/eclampsia superimposed on chronic hypertension.

A control was defined as a pregnant women enrolled in the antenatal care clinic of the hospital and who did not have a diagnosis of hypertensive disorders. For each case two controls were interviewed in the same day and the same facility where the case was identified. Besides, cases and controls were matched according to their parity category.

\section{Sample size determination and sampling procedure}

The sample size was calculated based on the comparison of proportions for matched case-control study using the following assumptions: Considering 95\% CI, $80 \%$ power, case to control ratio of $1: 2$ and taking different sample size were produced for different risk factor for hypertensive disorders of pregnancy. Maximum sample size was obtained taking History of paternal hypertension as a risk factor from a previous study in Cameroon [28] where the proportion of exposure among cases to be $17.4 \%$ and among controls, $6 \%$. Accordingly, these yields a maximum sample size of 100 cases and 200 controls. Adding a 10\% non-response rate, the final sample size required for the study was 110 cases and 220 controls.

All cases who fulfil the defined criteria were consecutively included until the desired sample size was obtained. For every case included, two controls who best matched were identified.

\section{Operational definitions [2]}

Hypertensive disorders of pregnancy- mother diagnosed with gestational hypertension, preeclampsia-eclampsia, chronic hypertension with superimposed preeclampsia or chronic hypertension (of any cause).

Gestational hypertension- systolic blood pressure $\geq$ $140 \mathrm{mmHg}$ and/or diastolic blood pressure $\geq 90 \mathrm{mmHg}$ measured on two occasions at least $4 \mathrm{~h}$ apart after twenty weeks of gestation in the absence of proteinuria or other systemic symptoms.

Preeclampsia- characterized by new onset of hypertension after 20 weeks gestation (systolic blood pressure $\geq 140$ $\mathrm{mmHg}$ and/or diastolic BP 290$) \mathrm{mmHg}$ and proteinuria. However, in the absence of proteinuria other manifestations such thrombocytopenia (platelet count less than $100,000 / \mu \mathrm{l}$ ), impaired liver function (elevated blood levels of liver transaminases to twice the normal concentration), the new development of renal insufficiency (elevated serum creatinine greater than $1.1 \mathrm{mg} / \mathrm{dl}$ or a doubling of serum creatinine in the absence of other renal disease), pulmonary edema, or new onset cerebral or visual disturbances are used to diagnose the case.

Eclampsia- characterized by new onset grand mal seizures in a woman with preeclampsia.

Chronic hypertension- includes essential hypertension as well as hypertension secondary to a range of conditions which is characterized by a blood pressure greater than or equal to $140 \mathrm{mmHg}$ systolic and/or $90 \mathrm{mmHg}$ diastolic confirmed before pregnancy or before $20 \mathrm{com}$ pleted weeks gestation.

Chronic hypertension superimposed with Preeclampsia - mothers known to have hypertension before pregnancy or before 20 weeks of gestation and who had developed signs of preeclampsia after 20 weeks of gestation.

Proteinuria- a dipstick result of $1+$ and above in a qualitative measurement. 


\section{Data collection}

Data collection was carried out in the maternity ward (antenatal care clinic and labor and delivery ward). It was collected by face to face interview technique using a pretested questionnaire. The questionnaire was developed following a thorough review of literatures from different sources and it included information related to socio-demographic condition, obstetrics and medical status, lifestyle and nutritional habits of the participants (Additional file 1). In addition to the questionnaire, patient medical records were reviewed to abstract relevant variables related with laboratory, clinical and obstetrics data. It was conducted by trained midwives and supervised by MPH professionals.

\section{Measurement}

Height was measured in standing position bare foot and expressed in centimetres while weight was recorded in killograms. Body mass index (BMI) was calculated as weight (pre-pregnancy weight in the preceding 3 months) divided by height in meter square $\left(\mathrm{kg} / \mathrm{m}^{2}\right)$. For those who failed to remember their pre-pregnancy weight, the measured weight in the first trimester was taken as the weight gain during this time is low. In areas where women do not book early for antenatal care as the case in developing countries, pregnancy BMI is not recommended. Hence, in this case the pre-pregnancy weight was considered to calculate body mass index. In addition maternal mid-upper arm circumference (MUAC) was measured as it is considered to be relatively stable during pregnancy [29].

Maternal height category was made according to the calculated percentiles of the study participant and classified into four groups: $\geq 160 \mathrm{~cm}$ (25th percentile and lower); 161-162 cm (26th to 50th percentile); 163-165 $\mathrm{cm}$ (51th to 75th percentile); and $\geq 166 \mathrm{~cm}$ (76th percentile and higher). Body mass index (BMI) defined as pre-pregnancy weight in kilogrammes divided by height in meters squared, was categorised as follows: underweight (BMI < 18.5); normal weight (BMI = 18.5-24.9); overweight $(\mathrm{BMI}=25-29.9)$; and obese $(\mathrm{BMI} \geq 30)$. Likewise, monthly income was categorized into the lowest 25 percentile (below \$91.9), between 25 and 75 percentile (\$92-183.7), and above 75 percentile (greater than $\$ 183.8$ ). Harvard university food frequency questionnaire [30] was used to assess the fruit and vegetables consumption status of mothers. Accordingly to the FFQ dietary assessment a list of fruits and vegetables were offered and asked how often they eat on average with in the last one year (ranging from never or less than once per month to $6+$ per day). Those women who consumed fruits more than 2-4 times per week were considered as regular consumers of fruits or vegetables. For coffee consumption both frequency and volume were assessed.

\section{Data quality control}

The questionnaire was prepared in English and translated into Tigrigna and back to English by independent language experts for consistency. Pre-test was conducted ahead of the actual data collection to see the appropriateness of the tool. Three days training was given for data collectors and supervisors on the content of the questionnaire and its administration. In order to maintain data quality primary data were collected from participants prospectively. The supervisors and the principal investigator checked questionnaires for completeness and inconsistencies on a daily basis.

\section{Analysis}

Data entry was done in EPI-info 7 and exported to STATA Version 14 for cleaning and analysis; data cleaning was also done. Descriptive summary measures are reported. To identify factors associated with hypertensive disorders of pregnancy bivariate and matched analysis was done for the outcome of interest by comparing the cases with controls. Moreover, crude matched odds ratio and their 95\% confidence intervals along with their $p$ values in conditional logistic regression were calculated. In multivariable analysis, matched analysis was performed using conditional logistic regression to identify risk factors of hypertensive disorders. Adjusted odds ratio and their 95\% confidence intervals were reported. Significance was declared at $P$-value $\leq 0.05$. Multi-collinearity was checked among the independent variables by running the regress and vif syntaxes in the stata software. Accordingly, the variance inflation factor $(V I F)$ was close to one and the tolerance which is the reciprocal of the variance inflation factor was also far above 0 which showed minimal collinearity. Post estimation command (Hosmer and Lemeshow test) in the logistic regression was run by using the estat gof to check the model fitness. Thus, the $p$-value for the Hosmer and Lemeshow chi-square was greater than 0.05 which indicated the fitness of the model. Overall findings were presented in texts and tables.

\section{Ethical consideration}

The study was approved by the institutional review board of the college of health sciences Addis Ababa University. Participants involved in the study voluntarily. There were no other risks for the participants to participate in the study, other than those encountered in day-to-day life. It was described that information obtained from this study may be of valuable to mothers and new-borns in general. The anonymity of the study was maintained by excluding personal identifiers from the data collection tool and the records of the study were kept strictly confidential. Finally Informed consent was sought from the participants. 


\section{Results}

\section{Socio-demographic characteristics}

A total of 330 mothers were interviewed in the data collection period that was held from June to November, 2018. Overall 110 cases matched on parity, day of interviews and study site/hospital with 220 controls taken part in the study to identify risk factors of hypertensive disorders of pregnancy. Of the total cases, gestational hypertension, preeclampsia, eclampsia and preeclampsia/eclampsia superimposed on chronic hypertension comprised of 36(32.7\%), 55(50\%), 14(12.7\%), and $5(4.5 \%)$ respectively. Respondents were predominantly married, Orthodox Christianity followers and Tigrian by ethnicity in both cases and controls (90\% and above in all cases). Regarding the occupation, majority of the mothers were housewives and comparable proportions were reported among cases and controls $(64.5 \% \mathrm{Vs}$ $68.2 \%)$. The Mean \pm (SD) age of cases and controls were $27.6 \pm 5.6$ and $26.7 \pm 5.8$ years respectively. The proportion of older age mothers (age $\geq 35$ ) was found to be higher among cases as compared to controls $(23.6 \% \mathrm{Vs}$ $11.8 \%)(P=.006)$. Besides, rural residents were higher among cases $71(64.5 \%)$ as compared to controls 76 (34.5\%) $(P<.001)$ (Table 1).

\section{Dietary, familial and lifestyle factors}

Twenty two (20\%) of pregnant mother had family history of hypertension among cases while only 14(6.4\%) pregnant women had family history of hypertension among controls. The mean pre-pregnancy weight of cases and controls were $53.6 \pm 8.4$ and $51.3 \pm 6.8 \mathrm{Kg}$, respectively. The maximum BMI recorded was 29.9 $\mathrm{kg} / \mathrm{m}^{2} ; 65(59.1 \%)$ and $147(66.8 \%)$ of the respondents had BMI ranging from 18.5 to $25 \mathrm{~kg} / \mathrm{m}^{2}$ in cases and controls respectively. The mid-upper arm circumference of mothers was categorized below the mean and above the mean $(\geq 22$. 1 and $>22.1)$ centimeters and more than $60 \%$ of the cases and controls were measured less than or equal to the mean. On average, the pre-pregnancy BMI was higher in women with hypertensive disorders than in those with normal pregnancies $(20.36 \pm 3.0$ Vs $19.8 \pm 2.6)(P=.05)$. Vegetable and fruit use were found to be less frequent in hypertensive disorders of pregnancy as compared with the normotensive women $(42.7 \%$ Vs 60.4 and $54.5 \%$ Vs $87.7 \%)$. Likewise, frequency and volume of coffee use was demonstrated to be higher among cases when compared with controls $(P=.01, P=.03)$ (Table 2).

\section{Obstetrics and medical factors}

The proportion of multiple pregnancy was $16.4 \%$ among cases, while it was $4.5 \%$ among controls ( $p=$ $0.001)$. On the other hand, average age at menarche was reported to be 15 years, which were similar among cases and controls. About 3\% of study participants had gestational diabetes mellitus and the proportion was different between cases and controls. It was $3.63 \%$ in cases while in controls it was $1.4 \%(P=0.02)$ (Table 3$)$.

\section{Risk factors of hypertensive disorders of pregnancy}

Bivariate analysis was run in the conductional logistic regression considering the discordant pairs between cases and controls to check the association between dependent and independent variables. Accordingly, rural residence, age $>=35$ years, family history of hypertension, infrequent use of vegetables/fruits, higher pre-pregnancy weight, body mass index, coffee use, gestational diabetes mellitus and pre-pregnancy oral contraceptive use were identified as risk factors. In contrast, There was no difference among cases and controls with regard to average age, marital status, religion, ethnicity, occupation, maternal educational level, husband's educational level, income, history of abortion, history of smoking, pre-pregnancy interval and age at menarche (Table 4).

Variables which were found to be associated with the outcome variable in the bivariate analysis $(P<=0.2)$ were taken to the multivariable analysis. This is basically to compensate for the power of the test since negative findings (that is, $p>0.05$ ) may be just because of inadequate power. After adjusting for possible confounding factors in the matched pair conditional logistic regression only residence, fruit use, pre-pregnancy BMI of mothers, types of pregnancy and gestational diabetes mellitus were found to be independent predictors of hypertensive disorders of pregnancy. Mothers who live in a rural area were at greater odds of having hypertensive disorders as compared to mothers who reside in urban area $(\mathrm{OR}=3.7,95 \% \mathrm{CI} ; 1.9,7.1)$. Similarly, mothers who do not consume at all or consume less amount of fruits in their diet had 5 times higher odds of developing hypertensive disorders than those who consume fruits regularly $(\mathrm{AOR}=5.195 \% \mathrm{CI}$; 2.4, 11.15). Overweight (BMI $\left.>25 \mathrm{Kg} / \mathrm{m}^{2}\right)$ mothers were also at risk of developing hypertensive disorders of pregnancy as compared with the normal and underweight mothers (AOR $=5.595 \% \mathrm{CI} ; 1.12,27.6)$. In addition, multiple pregnancy and presence of diabetes mellitus were independent risk factors for the development of hypertensive disorders of pregnancy; the risk of developing hypertensive disorders of pregnancy was 5.4 times higher among diabetic mothers compared with those who are free of the disease $(\mathrm{AOR}=5.4,95 \% \mathrm{CI}$; $1.1,27.0)$. On the other hand, the effect of age, family history of hypertension, use of vegetables, and drinking coffee disappeared in the multivariable analysis when adjusted for possible confounders. 
Table 1 Socio-demographic characteristics of mothers with and without hypertensive disorders of pregnancy in Tigray, 2018

\begin{tabular}{|c|c|c|c|c|}
\hline variable & HDP/Cases $N=110, N(\%)$ & No HDP/Controls N=220, N (\%) & COR $(95 \% \mathrm{Cl})$ & $P$-value \\
\hline \multicolumn{5}{|l|}{ Age group } \\
\hline$\leq 18$ & $7(6.4)$ & $10(4.6)$ & $1.5(0.58,4.1)$ & 0.378 \\
\hline $19-34$ & $77(70.0)$ & 184(83.6) & 1.0 & \\
\hline$\geq 35$ & $26(23.6)$ & 26(11.8) & $2.3(1.3,4.2)$ & 0.006 \\
\hline \multicolumn{5}{|l|}{ Residence } \\
\hline rural & $71(64.5)$ & $76(34.5)$ & $3.1(1.9,5.0)$ & $<0.001$ \\
\hline urban & $39(35.4)$ & 144(65.4) & 1.0 & \\
\hline \multicolumn{5}{|l|}{ Marital status } \\
\hline married & 104(94.5) & 199(90.5) & 1.0 & \\
\hline Unmarried & $6(5.4)$ & $21(9.5)$ & $0.5(0.2,1.4)$ & 0.2 \\
\hline \multicolumn{5}{|l|}{ Partner change } \\
\hline Yes & $14(12.7)$ & $26(11.8)$ & $1.09(0.5,2.2)$ & 0.8 \\
\hline No & $96(87.2)$ & 194(88.2) & 1.0 & \\
\hline \multicolumn{5}{|l|}{ Religion } \\
\hline orthodox & 103(93.6) & 199(90.5) & $1.4(0.5,3.6)$ & 0.49 \\
\hline Muslim & $6(5.5)$ & $16(7.3)$ & 1.0 & \\
\hline \multicolumn{5}{|l|}{ Maternal education } \\
\hline literate & $74(67.3)$ & 153(69.5) & 1.0 & \\
\hline illiterate & $36(32.7)$ & $67(30.5)$ & $1.12(0.7,1.9)$ & 0.65 \\
\hline \multicolumn{5}{|l|}{ Ethnicity } \\
\hline Tigrian & 105(95.5) & 200(90.9) & 1.0 & \\
\hline Amhara & $4(3.6)$ & $17(7.7)$ & $0.4(0.14,1.36)$ & 0.15 \\
\hline \multicolumn{5}{|l|}{ Occupation } \\
\hline Housewife & $71(64.5)$ & $150(68.2)$ & 1.0 & \\
\hline Government employee & $22(20.0)$ & $33(15)$ & $1.4(0.7,2.7)$ & 0.26 \\
\hline NGO employee & $8(7.3)$ & $7(3.2)$ & $2.5(0.8,7.7)$ & $\begin{array}{l}0.08 \\
0.17\end{array}$ \\
\hline Private employee & $7(6.4)$ & $28(12.7)$ & $0.5(0.2,1.3)$ & \\
\hline \multicolumn{5}{|l|}{ Husband education } \\
\hline Illiterate & $14(12.7)$ & $31(14.1)$ & $0.9(0.4,1.9)$ & 0.8 \\
\hline Read and write & $14(12.7)$ & $26(11.82)$ & $1.1(0.5,2.3)$ & 0.7 \\
\hline Primary & 23(20.9) & $42(19.1)$ & $1.1(0.6,2.1)$ & 0.6 \\
\hline Secondary and above & 59(53.6) & $122(55)$ & 1.0 & \\
\hline \multicolumn{5}{|l|}{ Income category } \\
\hline$\leq 2500$ & 37 (33.64) & $62(28.18)$ & $0.8(0.4,1.5)$ & 0.5 \\
\hline $2501-4999$ & $48(43.64)$ & $106(48.18)$ & $0.9(0.5,1.7)$ & 0.8 \\
\hline$\geq 5000$ & $25(22.73)$ & $52(23.64)$ & 1.0 & \\
\hline
\end{tabular}

\section{Discussion}

The current study result showed that rural residence was associated with the development of hypertensive disorder of pregnancy. This finding is consistent with a previous finding in an epidemiological study among pregnant mothers in Cairo, Egypt [23]. This could be due to the fact that mothers from rural areas book antenatal care later in pregnancy and have fewer ANC visits which could be associated with delay in health seeking behaviour. This delay in health care seeking could in turn be influenced by lack of awareness on pregnancy related problems, husband and 
Table 2 Dietary, familial and lifestyle characteristics of mothers with/without hypertensive disorders of pregnancy in Tigray, 2018

\begin{tabular}{|c|c|c|c|c|}
\hline variable & $\begin{array}{l}\text { HDP/Cases } \\
N=110, N(\%)\end{array}$ & $\begin{array}{l}\text { No HDP/Controls } \\
N=220, N(\%)\end{array}$ & $\begin{array}{l}\text { COR } \\
(95 \% \mathrm{Cl})\end{array}$ & $P$-value \\
\hline \multicolumn{5}{|l|}{ Family history of hypertension } \\
\hline Yes & $22(20)$ & $14(6.4)$ & $3.6(1.7,7.6)$ & 0.001 \\
\hline No & $88(80)$ & $206(93.6)$ & 1.0 & \\
\hline Mean weight $\pm(\mathrm{SD})$ & $63.2(8.7)$ & $60.8(7.3)$ & & 0.01 \\
\hline Mean Height $\pm(S D)$ & $1.61(.06)$ & 1.62(.05) & & 0.09 \\
\hline \multicolumn{5}{|l|}{ MAUC } \\
\hline$\leq 22.1$ & $69(62.7)$ & $140(63.6)$ & 1.0 & \\
\hline$>22.1$ & $41(37.3)$ & $80(36.4)$ & $1.0(0.6,2.0)$ & 0.82 \\
\hline Pre-pregnancy mean weight \pm (SD) & $53.6(8.4)$ & $51.3(6.8)$ & & 0.006 \\
\hline Pre-pregnancy mean $\mathrm{BMI} \pm$ (SD & $20.36(3.0)$ & $19.8(2.6)$ & & 0.05 \\
\hline \multicolumn{5}{|l|}{ Fruit use } \\
\hline Yes & $60(54.5)$ & 193(87.7) & 1.0 & \\
\hline No & $50(45.5)$ & $27(12.3)$ & $5.3(3.0,9.4)$ & $<0.001$ \\
\hline \multicolumn{5}{|l|}{ Vegetable use } \\
\hline Yes & $47(42.7)$ & 133(60.4) & 1.0 & 0.002 \\
\hline No & $63(57.3)$ & 87(39.6) & $2.1(1.3,3.3)$ & \\
\hline \multicolumn{5}{|l|}{ BMI of mothers } \\
\hline$<18.5$ & $33(30.0)$ & $67(30.5)$ & 1.0 & \\
\hline $18.5-24.9$ & $65(59.1)$ & $147(66.8)$ & $0.9(0.6,1.6)$ & 0.8 \\
\hline$\geq 25$ & $12(10.9)$ & $6(2.7)$ & $4.3(1.4,13.6)$ & 0.01 \\
\hline \multicolumn{5}{|l|}{ Coffee use } \\
\hline Yes & $93(84.5)$ & 149(67.7) & $3.0(1.6,5.9)$ & 0.001 \\
\hline No & $17(15.5)$ & $71(32.3)$ & 1.0 & \\
\hline \multicolumn{5}{|l|}{ Frequency of coffee use $(N=242)$} \\
\hline$\geq$ once a day & $76(81.7)$ & $104(69.8)$ & $3.2(1.3,8.3)$ & 0.01 \\
\hline$<$ once a day & $17(18.3)$ & $45(30.2)$ & 1.0 & \\
\hline \multicolumn{5}{|l|}{ volume of coffee use $(N=242)$} \\
\hline$<3$ cups & 28(30.1) & $69(46.3)$ & 1.0 & \\
\hline$\geq 3$ cups & 65(69.9) & $80(53.7)$ & $2.1(1.0,4.1)$ & 0.03 \\
\hline
\end{tabular}

family influences, local cultural influence and bad experiences in health facilities.

Similarly fruit consumption was found to be important predictor in this study, mothers who consume less fruits in their diets were at higher risk of developing hypertensive disorders of pregnancy which is in line with previous findings reported from Bahrdar, Ethiopia ([19], Cairo, Egypt [23] and Norway [17]. This was also supported by a systematic review and meta-analysis of studies whereby calcium intake was found to be protective to hypertensive disorders of pregnancy in a multivariable analysis [31]. Fruits are rich in micronutrients and many of the vitamins and minerals play antioxidant role which could in turn help in the prevention of hypertensive disorders of pregnancy.
Pre-pregnancy body mass index was calculated and overweight mothers were at higher odds of developing hypertensive disorders of pregnancy as compared with low and normal body mass index which is in agreement with reports from USA [32, 33]. Likewise, multiple pregnancy has been reported as an independent predictor of hypertensive disorders of pregnancy from various studies in different parts of the globe [22, 34, 35]. The current finding is also in support of those previous reports which showed 4.2 times increased risk of developing hypertensive disorders of pregnancy compared with the singleton pregnancy.

Gestational diabetes mellitus was also found to be an independent predictor of hypertensive disorders of pregnancy that supported the existing knowledge; because literatures noted that pregnant mother who developed 
Table 3 Obstetrics and medical characteristics of mothers with/ without hypertensive disorders of pregnancy in Tigray, 2018

\begin{tabular}{|c|c|c|c|c|}
\hline Variable & $\begin{array}{l}\text { HDP/Cases } \\
N=110, N(\%)\end{array}$ & $\begin{array}{l}\text { No HDP/Controls } \\
N=220, N(\%)\end{array}$ & $\begin{array}{l}\text { COR } \\
(95 \% \mathrm{Cl})\end{array}$ & $P$-value \\
\hline \multicolumn{5}{|c|}{ Pregnancy type } \\
\hline Multiple & $18(16.4)$ & $10(4.5)$ & $4.1(1.8,9.6)$ & 0.001 \\
\hline Single & $92(83.6)$ & $210(95.5)$ & 1.0 & \\
\hline \multicolumn{5}{|c|}{ Gestational diabetes mellitus } \\
\hline Yes & $7(6.36)$ & $3(1.4)$ & $4.7(1.2,18.0)$ & 0.02 \\
\hline No & $103(93.6)$ & $217(98.6)$ & 1.0 & \\
\hline \multicolumn{5}{|c|}{ Pre-pregnancy oral contraceptive use } \\
\hline Yes & $42(38.2)$ & $63(28.6)$ & $1.5(0.9,2.4)$ & 0.08 \\
\hline No & $68(61.8)$ & $157(71.4)$ & 1.0 & \\
\hline \multicolumn{5}{|c|}{ Presence of anemia at first visit } \\
\hline Yes & $94(85.5)$ & 194(88.2) & $1.3(0.6,2.9)$ & \\
\hline No & $16(14.5)$ & 26(11.8) & 1.0 & 0.43 \\
\hline \multicolumn{5}{|c|}{ Age at menarche } \\
\hline$\leq 15$ years & $72(65.4)$ & $148(67.3)$ & $0.9(0.6,1.5)$ & 0.734 \\
\hline$>15$ years & $38(34.6)$ & $72(32.7)$ & 1.0 & \\
\hline \multicolumn{5}{|c|}{ Pre-pregnancy interval $(N=216)$} \\
\hline$<5$ years & $54(83.08)$ & $117(77.5)$ & 1.0 & \\
\hline$\geq 5$ years & $11(16.92)$ & $34(22.5)$ & $0.9(0.4,2.2)$ & 0.88 \\
\hline \multicolumn{5}{|c|}{ History of abortion } \\
\hline Yes & $25(22.7)$ & $39(17.7)$ & 1.0 & 0.263 \\
\hline No & 85 (77.3) & $181(82.3)$ & $0.7(0.4,1.2)$ & \\
\hline
\end{tabular}

diabetes mellitus would have higher predisposition to develop hypertensive disorders of pregnancy and it has been identified as the most common predictor in previous studies [22, 34, 36-38].

Family history of hypertension was a predictor in the bivariate analysis but its effect vanished in the adjusted model and this contradicts with previous reports. These studies reported an increased risk of hypertensive disorders with a positive family history of chronic hypertension [21, 28, 36, 39-41].

Similarly, drinking more than 3 cups of coffee per day was not a significant risk factor in this study which means it is in conformity with some studies showing no difference [42] and contradicted with others. For instance, a study in Bahrdar, Ethiopia showed that mothers who reported to have taken coffee during pregnancy had higher odds of developing preeclampsia [19]. However, another study in Rotterdam, the Netherlands reported the substantial protection of coffee against the development of pregnancy induced hypertension [42].

Extreme lower or higher ages in pregnancy (age $<20$ and $>35$ years) were reported as a risk factor for hypertensive disorders of pregnancy in previous
Table 4 Bivariate and multivariable analysis for the predictors of hypertensive disorders of pregnancy in Tigray, 2018

\begin{tabular}{|c|c|c|}
\hline Variables & $\begin{array}{l}\text { Matched unadjusted } \\
\text { OR( } 95 \% \mathrm{Cl})\end{array}$ & $\begin{array}{l}\text { Matched adjusted } \\
\text { OR(95\% Cl) }\end{array}$ \\
\hline \multicolumn{3}{|l|}{ Residence } \\
\hline Rural & $3.1(1.9,5.0)^{*}$ & $3.7(1.9,7.1)^{* *}$ \\
\hline Urban & 1.0 & 1.0 \\
\hline \multicolumn{3}{|l|}{ Age } \\
\hline Mean $\pm(S D)$ & $1.02(0.9,1.06)$ & $0.96(0.9,1.02)$ \\
\hline \multicolumn{3}{|l|}{ Marital status } \\
\hline Married & 1.0 & 1.0 \\
\hline Unmarried & $0.5(0.2,1.4)$ & $0.44(0.12,1.5)$ \\
\hline \multicolumn{3}{|c|}{ Family History of hypertension } \\
\hline Yes & $3.6(1.7,7.6)^{*}$ & $2.1(0.7,6.4)$ \\
\hline No & 1.0 & 1.0 \\
\hline \multicolumn{3}{|l|}{ Fruit use } \\
\hline Yes & 1.0 & 1.0 \\
\hline No & $5.3(3.0,9.4)^{*}$ & $5.1(2.4,11.15)^{* *}$ \\
\hline Vegetable use & & 1.0 \\
\hline Yes & 1.0 & $1.2(0.6,2.3)$ \\
\hline No & $2.08(1.3,3.3)^{*}$ & \\
\hline \multicolumn{3}{|c|}{ History of smoking } \\
\hline Yes & 1.0 & 1.0 \\
\hline No & $0.3(0.07,1.2)$ & $0.6(0.07,5.2)$ \\
\hline \multicolumn{3}{|c|}{ BMI of mothers (prepregnancy) } \\
\hline$<18.5$ & 1.0 & 1.0 \\
\hline $18.5-24.9$ & $0.95(0.56,1.6)$ & $1.7(0.8,3.4)$ \\
\hline $25-29.9$ & $4.3(1.4,13.6)^{*}$ & $5.5(1.12,27.6)^{*}$ \\
\hline \multicolumn{3}{|l|}{ Coffee use } \\
\hline Yes & $3.08(1.6,5.9)^{*}$ & $1.9(0.8,4.4)$ \\
\hline No & 1.0 & 1.0 \\
\hline
\end{tabular}

Pregnancy type

$\begin{array}{lll}\text { multiple } & 4.1(1.8,9.6)^{*} & 4.2(1.3,13.3)^{*} \\ \text { single } & 1.0 & 1.0\end{array}$

Presence of gestational diabetes mellitus

$\begin{array}{lll}\text { Yes } & 4.6(1.2,18.0)^{*} & 5.4(1.1,27.0)^{*}\end{array}$

No $\quad 1.0 \quad 1.0$

Oral contraceptive use

$\begin{array}{lll}\text { Yes } & 1.5(0.9,2.4) & 1.2(0.6,2.4)\end{array}$

$\begin{array}{lll}\text { No } & 1.0 & 1.0\end{array}$

${ }^{*} P$-value $<0.01,{ }^{* * P}$-value $<0.001$

studies; Tebeu PM et.al reported that teenage mothers were at increased risk of developing hypertensive disorders [28] on the other hand, Suzuki. S. and Igarashi $M$. in their study revealed that age $>=35$ was a significant factor for the development of preeclampsia [43] but in the current study though age $>=35$ 
showed a significant risk in the first model, no difference was observed in the adjusted model. The difference may be due to the fact that majority of the respondents were within the age range of 19-34.

In many studies nulliparity was reported as a common risk factor for the development of hypertensive disorders of pregnancy [32-34, 41] but in this study its effect was not possible to measure as it was a matching variable. Unlike the current finding, partner change was reported as a risk factor for hypertensive disorders of pregnancy in other literatures [23]. The reason may be there were few mothers who changed their partner in the study and this in turn could make the difference invisible.

In previous studies illiteracy was reported to be a risk factor for hypertensive disorders of pregnancy [28] as it affects the age at marriage and pregnancy as well as health seeking behaviour but in the current study no association was reported. The continuous health education program provided by the health extension workers at the community and household levels might have helped to have similar level of awareness about the issue.

Some studies reported inter-pregnancy interval as a risk factor for hypertensive disorders of pregnancy. Longer inter-pregnancy interval had higher risk of developing hypertensive disorders of pregnancy [44] but in the current study no association was found.

The aforementioned findings should be viewed in light of the following limitations. Since cases were selected consecutively as soon as they were identified, selection bias might be introduced. Moreover, dietary assessment was self-reported and assessed at diagnosis which could have introduced recall bias.

\section{Conclusion}

The study assessed different risk factors of hypertensive disorders of pregnancy. Thus, rural residence, less fruit consumption, multiple pregnancy, presence of gestational diabetes mellitus and pre-pregnancy overweight were identified as independent risk factors. This highlights that there is a need to extend obstetric services to the grass root level in which rural residents can get all types of services in a closer distance. In addition, it necessitates strong nutritional education for the community during pregnancy and even the time preceding pregnancy including the routine supply of supplements. There is also a need to remind health professionals to properly identify and manage pregnant women having diabetes mellitus. It is recommended that these factors can be used as a screening tool for the prediction, early diagnoses as well as timely interventions of hypertensive disorders of pregnancy.

\section{Additional file}

Additional file 1: The tool used to collect the information (caes-control study) has been attached as additional file. (DOCX $30 \mathrm{~kb}$ )

\section{Abbreviations \\ ACOG: American College of Obstetricians and Gynaecologists; \\ BEmONC: Basic Emergency Obstetrics and Newborn Care; BMI: Body Mass Index; EmONC: Emergency Obstetric and Newborn Care; HDP: Hypertensive Disorders of Pregnancy; ICD: International Classification of Disease; MPH: Master of Public Health; MUAC: Mid Upper Arm Circumference; WHO: World Health Organization}

\section{Acknowledgements}

The authors would like to extend their gratitude to the study participants for their consensual participation. Likewise, the authors would like to thank data collectors and supervisors for their commitment throughout the data collection process. Finally, special gratitude goes to Mekelle and Addis Ababa universities for funding the study.

\section{Funding}

The study was funded by both Addis Ababa and Mekelle universities.

\section{Availability of data and materials}

The STATA dataset for the current study is available from the corresponding author on reasonable request.

\section{Authors' contributions}

HBK is the primary author, participated in the conceptualization, design, acquisition, analysis and interpretation of the data and drafted the manuscript. FEG was the primary academic advisor, contributed for design, acquisition, analysis and interpretation of the data and critically revised the manuscript. WMA was co-advisor, contributed for design, acquisition, analysis and interpretation of the data and critically revised the manuscript for important intellectual content. All authors read and approved the final manuscript.

\section{Ethics approval and consent to participate}

The Institutional Review Board of College of Health Sciences, Addis Ababa University approved the study on 15/06/2017 (ref: 035/17/SPH). According to the Institutional Review Board of Addis Ababa University, taking verbal consent is the standard requirement for observational studies. Hence, the participants gave verbal consent to be enrolled in the study after they received an adequate briefing on the purpose and procedure of the study. For women aged less than 18 years verbal consent was obtained from their parents or husbands. The anonymity of all participating women was ensured by not recording any names or other personal identifiers. Their right not to participate, not to answer any or all questions and to withdraw from the interview at any time they want was respected.

Consent for publication

Not applicable

\section{Competing interests}

The authors declare that they have no competing interests.

\section{Publisher's Note}

Springer Nature remains neutral with regard to jurisdictional claims in published maps and institutional affiliations.

\section{Author details}

${ }^{1}$ School of Nursing, Mekelle University, P.O.Box:1871, Mekelle, Ethiopia.

${ }^{2}$ School of Public Health, Addis Ababa University, Addis Ababa, Ethiopia. 
Received: 28 May 2018 Accepted: 20 November 2018

Published online: 06 December 2018

\section{References}

1. Lowe SA, Bowyer L, Lust K, McMahon LP, Morton M, North RA. et al., SOMANZ guidelines for the management of hypertensive disorders of pregnancy 2014. Aust N Z J Obstet Gynaecol 55(5)e1-29.

2. American college of obstetricians and gynecologists (ACOG). Hypertension in Pregnancy (Report of the ACOG Task Force on Hypertension in Pregnancy). Obstet Gynecol. 2013;122(5):1122-31.

3. National Institute for Health and Clinical Excellence (NICE). Hypertension in pregnancy: the management of hypertensive disorders during pregnancy. In: National Collaborating Centre for Women's and Children's health; 2010

4. Cunningham F, Leveno K, Bloom S, Hauth J, Rouse D, Spong C. Williams Obstetrics 22rd Edition. New York: McGraw Hill. Companies Inc; 2005. Chapter 34, Hypertensive disorders in pregnancy; p. 426-50.

5. Say L, Chou D, Gemmill A, Moller AB, Daniels J, Temmerman M ea. Global causes of maternal death: a WHO systematic analysis. Lancet Glob Health. 2014;2(6):e323-33.

6. Khan KS, Wojdyla D, Say L, Gülmezoglu M, Van Look P. WHO analysis of causes of maternal death: a systematic review. Lancet. 2006;367(9516):1066-74.

7. Steegers EA, Von Dadelszen P, Duvekot JJ, Pijnenborg R. Pre-eclampsia. Lancet. 376(9741):631-44.

8. EngenderHealth, Balancing the Scales Expanding Treatment for Pregnant Women with Life-Threatening Hypertensive Conditions in Developing Countries A Report on Barriers and Solutions to Treat Pre-eclampsia \& Eclampsia New York. 2007

9. Gaym A, Bailey P, Pearson L, Admasu K, Gebrehiwot Y. Disease burden due to preeclampsia/eclampsia and the Ethiopian health system's response. Int J Gynecol Obstet. 115(1):112-6.

10. Garomssa H, Dwivedi A. Maternal mortality in ambo hospital: a five year retrospective review. Ethiop J Reprod Health. 2008;2(1):1-13.

11. FDRE-MOH, Health sector transformation plan (HSTP) 2015/16-2019/20. 2015: p. 2529.

12. Association of Ontario Midwives. Hypertensive disorders of pregnancy. (clinical practice guideline no. 15), 2012

13. Wolde Z, Segni H, Woldie M. Hypertensive disorders of pregnancy in Jimma University Specialized Hospital. Ethiopian journal of health sciences. 2011; 21(3):147-54.

14. Kaaja R. Predictors and risk factors of pre-eclampsia. Minerva Ginecol. 2008; 60(5):421-9.

15. Kichou B, Henine N, Kichou L, Benbouabdellah M. Epidemiology of preeclampsia in Tizi-ouzou city (Algeria). in Annales de cardiologie et d'angeiologie.

16. Levenson JW, Skerrett PJ, Gaziano JM. Reducing the global burden of cardiovascular disease: the role of risk factors. Prev Cardiol. 2002;5(4):188-99.

17. Brantsæter AL, Haugen M, Samuelsenet SO, Torjusen H, Trogstad L, Alexander J. A dietary pattern characterized by high intake of vegetables, fruits, and vegetable oils is associated with reduced risk of preeclampsia in nulliparous pregnant Norwegian women. J Nutr. 2009;139(6):1162-8.

18. Atkinson JO, Mahomed KW, Michelle A, Woelk GB, Mudzamiri S. Weiss. Dietary risk factors for pre-eclampsia among women attending Harare maternity hospital, Zimbabwe. Cent Afr J Med. 1998:44(4):86-92.

19. Endeshaw M, Ambaw F, Aragaw A, Ayalew A. Effect of maternal nutrition and dietary habits on preeclampsia: a case-control study. International Journal of Clinical Medicine. 5(21):1405.

20. Guerrier G, Oluyide B, Keramarou M, Grais RF. Factors associated with severe preeclampsia and eclampsia in Jahun, Nigeria. Int J Women's Health. 2013:5:509.

21. Dalmáz CA, Dos Santos KG, Botton MR, Roisenberg I. Risk factors for hypertensive disorders of pregnancy in southern Brazil. Rev Assoc Med Bras. 57(6):692-6

22. Conde AA, Belizan JM. Risk factors for preeclampsia in a large cohort of Latin American and Caribbean women. BJOG Int J Obstet Gynaecol. 2000; 107(1):75-83.

23. El-Moselhy EA, Khalifa HO, Soliman M, Mohammad Kl, Abd El-Aal HM. Risk factors and impacts of pre-eclampsia: an epidemiological study among pregnant mothers in Cairo Egypt. Journal of American Science. 2011;7(5):311-23.

24. Gidey G, Bayray A, Gebrehiwot H. Patterns of maternal mortality and associated factors; a case-control study at public hospitals in Tigray region, Ethiopia, 2012. Int J Pharm Sci Res. 2013;4(5):1918.
25. Terefe W, Getachew Y, Hiruye A, Derbew M, Hailemariam D, Mammo D. et. al. Patterns of hypertensive disorders of pregnancy and associated factors at Debre Berhan Referral Hospital, North Shoa, Amhara Region. Ethiop Med J. 2015; supplement 2:57-65.

26. Ethiopia federal democratic republic, $\mathrm{MOH}$. Health \& health-related indicators 2016/2017, 2010

27. $\mathrm{WHO}$, the $\mathrm{WHO}$ Application of ICD-10 to deaths during pregnancy, childbirth and the puerperium: ICD-MM. 2012

28. Tebeu P, Foumane P, Mbu R. Risk factors for hypertensive disorders in pregnancy: a report from the maroua regional hospital, cameroon. J Reprod Infertil. 2011:12(3):227-34.

29. WHO, maternal anthropometry and pregnancy outcomes. A WHO collaborative study. World Health Organization Supplement. 1995;73:32-7.

30. Harvard university Food frequency assessment questionnaire, Dietary assessment 2007.https://regepi.bwh.harvard.edu/health/nutrition.htm ctrc/ Nutrition/Documents/Food_Frequency_Questionnaires.pdf.

31. Schoenaker DA, Soedamah-Muthu SS, Mishra GD. The association between dietary factors and gestational hypertension and pre-eclampsia: a systematic review and metaanalysis of observational studies. BMC Med. 2014;12(157):1-18.

32. Eskenazi $\mathrm{BL}$, Fenster $\mathrm{L}$, Sidney $\mathrm{S}$. A multivariate analysis of risk factors for preeclampsia. JAMA. 1991;266(2):237-41.

33. Turzanski F, Shannon R. Modifiable risk factors for hypertensive disorders of pregnancy among Latina women; 2009

34. Dawson LM, Parfrey PS, Hefferton D, Dicks EL, Cooper MJ, Young D. Familial risk of preeclampsia in Newfoundland: a population-based study. J Am Soc Nephrol. 2002;13(7):1901-6.

35. Duckitt K, Harrington D. Risk factors for pre-eclampsia at antenatal booking: systematic review of controlled studies. BMJ. 2005;330(7491):565.

36. Shamsi U, Hatcher J, Shamsi A, Zuberi N, Qadri Z, Saleem S. A multicentre matched case control study of risk factors for preeclampsia in healthy women in Pakistan. BMC Womens Health. 2010;10(14):1-7.

37. Ota E, Ganchimeg T, Mori R, Souza JP. Risk factors of pre-eclampsia/ eclampsia and its adverse outcomes in low-and middle-income countries: a WHO secondary analysis. PLoS One. 2014;9(3):1-9.

38. Suleiman AK. Risk factors on hypertensive disorders among Jordanian pregnant women. Global J Health Sci. 2014;6(2):138-44.

39. Tessema GA, Tekeste A, Ayele TA. Preeclampsia and associated factors among pregnant women attending antenatal care in Dessie referral hospital, Northeast Ethiopia: a hospital-based study. BMC pregnancy and childbirth. 2015;15(73):1-7.

40. Nanjundan P, Bagga R, Kalra JK, Thakur JS, Raveendran A. Risk factors for early onset severe pre-eclampsia and eclampsia among north Indian women. J Obstet Gynaecol. 2011;31(5):384-9.

41. Sultana AJ, Aparna J. Risk factors for pre-eclampsia and its perinatal outcome. Annals of biological research. 2013;4(10):1-5.

42. van der Hoeven T, Browne JL, Uiterwaal $\mathrm{C}$, et al. Antenatal coffee and tea consumption and the effect on birth outcome and hypertensive pregnancy disorders. PLoS One. 2017:12(5):1-12.

43. Suzuki S, Igarashi M. Risk factors for preeclampsia in Japanese twin pregnancies: comparison with those in singleton pregnancies. Arch Gynecol Obstet. 2009;280(3):389-93.

44. Harutyunyan A, Armenian H, Petrosyan V. Investigation of risk factors for preeclampsia development among reproductive age women living in Yerevan, Armenia: a case-control study. Yerevan: College of Health Sciences, American University of Armenia; 2009.

Ready to submit your research? Choose BMC and benefit from:

- fast, convenient online submission

- thorough peer review by experienced researchers in your field

- rapid publication on acceptance

- support for research data, including large and complex data types

- gold Open Access which fosters wider collaboration and increased citations

- maximum visibility for your research: over $100 \mathrm{M}$ website views per year

At BMC, research is always in progress.

Learn more biomedcentral.com/submissions 